\title{
Toelating tot de medische opleiding in beweging. Capaciteit en legitimiteit
}

\author{
J.A. Dekker, M.M.C. Lambregts, M.W. Heeren, J.I. Hanemaayer, namens het KNMG Studentenplatform*
}

\section{Samenvatting}

Sinds de jaren zeventig kent Nederland een instroombeperking voor de opleiding Geneeskunde. Dit artikel geeft een overzicht van de (politieke) ontwikkelingen die sindsdien op dit gebied hebben plaatsgevonden. Er is aandacht voor zowel de wijze van selectie als de hoogte van de instroom.

Na een langdurige politieke afweging zijn er anno 2009 drie manieren om toegang te krijgen tot de opleiding Geneeskunde: directe toelating vanwege een examengemiddelde hoger dan een acht, gewogen loting en decentrale selectie. Alle genoemde methoden hebben beperkingen, maar een combinatie van de drie verzacht de nadelen van de afzonderlijke methoden. Momenteel is het beleid gericht op een overschot aan basisartsen met als doel marktwerking. Nadelen hiervan zijn verlies van kwaliteit van de opleiding en werkloosheid onder (basis)artsen. Kortom: de numerus fixus is een onvolmaakt systeem waarin verschillende belangen conflicten veroorzaken.

Gezien de huidige ontwikkelingen (de uitwerking van het bachelor/mastersysteem en de marktwerking) kunnen we concluderen dat het systeem van instroombeperking nog voor voldoende uitdagingen zal komen te staan. (Dekker JA, Lambregts MMC, Heeren MW, Hanemaayer J.I. Toelating tot de medische opleiding in beweging. Capaciteit en legitimiteit. Tijdschrift voor Medisch Onderwijs 2009; 28(4)159-166).

\section{Inleiding}

Al sinds de jaren zestig is er discussie over de legitimiteit en de hoogte van de instroombeperking van de medische opleiding, waarbij er ook aandacht is voor de wijze waarop de instroom wordt gerealiseerd. Dit artikel besteedt zowel aandacht aan het capaciteitsvraagstuk als aan de wijze van selectie. Allereerst komt de historie aan bod, gevolgd door de wijzen waarop de instroom gerealiseerd wordt (directe toegang, loting, decentrale selectie). Daarna is er aandacht voor instroomregulatie en de hoogte van de numerus fixus, met tot slot een blik op de toekomst. Al met al blijkt dat de problematiek rondom deze vraagstukken nog steeds actueel is.

\section{Historie van de instroombeperking van de medische opleiding}

In 1959 voerde de Utrechtse faculteit voor Tandheelkunde eigenmachtig een beperking van de instroom van eerstejaars in. Hiermee was voor het eerst in Nederland bij een medische opleiding de numerus clausus (autonome instroombeperking) een feit. Alle studenten die niet in Utrecht mochten beginnen konden wel voor de-

\footnotetext{
* Het KNMG Studentenplatform is een landelijke en onafhankelijke belangenbehartiger van studenten geneeskunde. Het platform houdt zich bezig met maatschappelijke en onderwijskundige onderwerpen die studenten geneeskunde in heel Nederland aangaan en die de lokale situatie op de medische faculteiten overstijgen. De standpunten van het KNMG Studentenplatform worden zoveel mogelijk gebaseerd op representatief (opinie)onderzoek (www.knmgstudentenplatform.nl)
} 
zelfde studie in Groningen terecht. Het evenwicht tussen het aantal studenten en de beschikbare ruimte en middelen per faculteit speelden bij dit besluit een rol met als uiteindelijk doel het optimaliseren van de kwaliteit van het onderwijs. ${ }^{1}$ Een jaar later introduceerde de opleiding Geneeskunde in Hamburg een lotingprocedure. Pas in de jaren daarna kwam in de Haagse politiek de mogelijkheid van een numerus fixus voor geneeskunde aan de orde.

Een numerus fixus is een wijze van instroombeperking waarin niet het belang van de kwaliteit van het onderwijs aan een bepaalde faculteit, maar de behoefte van de gemeenschap aan onderwijscapaciteit centraal staat. ${ }^{2}$ De Tweede Kamer vond destijds dat een instroombeperking in strijd was met de vrijheid van studiekeuze van studenten en koos een andere oplossing voor het toenmalige opleidingscapaciteitsprobleem, namelijk uitbreiding van de capaciteit. Dit leidde in 1966 tot de door de overheid ingestelde Medische Faculteit Rotterdam. Het aantal studenten bleef in de jaren daarop echter gestaag toenemen en in 1972 werd uiteindelijk toch een wettelijke studentenstop met loting ingevoerd. Een jaar later adviseerde de commissie Wiegersma (Werkgroep Selectie) een gemengd systeem in te voeren, waarin een deel van de opleidingsplaatsen direct beschikbaar is voor gegadigden met de hoogste eindexamencijfers en de overige plekken worden verloot. Met het deels overnemen van dit advies werd in 1975 de gewogen loting een feit. Een jaar later adviseert ook de commissie Warries (Adviescommissie Toelatingscriteria W.O.) om kandidaten met een hoog eindexamengemiddelde direct toe te laten.

Er blijft echter veel tegenstand, zeker als er in 1978 aanwijzingen zijn dat er geen verband bestaat tussen hoge eindexamencijfers en studieresultaten. ${ }^{3}$ De toenmalige minister Pais van Onderwijs liet daarom voor de studies met een numerus fixus toelatingstoetsen ontwikkelen, die de gewogen loting moesten gaan vervangen. Ook deze voorgestelde toelatingstoets zal het niet redden als selectiemethode; het voorstel wordt in 1982 afgeblazen. Het geval van Meike Vernooy, een scholiere met maar liefst een 9,6 als gemiddelde voor haar eindexamen, was wel aanleiding om ' $8+$ scholieren' voortaan direct toegang te verlenen tot de medische opleiding. Vernooy werd drie maal uitgeloot (1996, 1997, 1998). Ze zocht in de media aandacht en startte diverse procedures om alsnog toegang te krijgen tot de opleiding, hetgeen in september 1999 gebeurde.

Anno 2009 is er nog steeds sprake van een instroombeperking, waarbij de instroom via drie kanalen verloopt: directe toelating, gewogen loting en decentrale selectie.

\section{Directe toelating en loting}

De Informatie Beheer Groep voert de centrale toelating voor de opleiding Geneeskunde uit door middel van loting. Er bestaan vijf klassen. De eerste klasse is de groep met een eindexamengemiddelde hoger dan of gelijk aan een acht en wordt rechtstreeks toegelaten tot de faculteit van hun keuze. In de lagere klassen is sprake van een gewogen loting. Hoe hoger het gemiddelde eindexamencijfer des te groter de kans om aan de studie geneeskunde te mogen beginnen. Klasse twee is voor de groep scholieren met een eindexamengemiddelde lager dan een acht maar hoger dan een zeven en een half. De opvolgende klassen zijn steeds een half punt lager. Het lot bepaalt dus of iemand met een eindexamencijfer lager dan een acht wordt ingeloot, maar naarmate het eindexamengemiddelde hoger is, wordt de kans op inloten groter. ${ }^{4}$

Cohen et al. onderzochten de relatie tussen eindexamencijfers en het studiesucces, carrièreontwikkeling en wetenschappelijke prestaties van (medisch) studenten, 
die in de studiejaren 1982 en 1983 waren toegelaten tot de opleiding Geneeskunde. Er werd een significant verband geconstateerd tussen de hoogte van de eindexamencijfers met de studieduur, met de kans om een gewenste specialisatie te doen en met de hoogte van de wetenschappelijke output. ${ }^{5}$ Deze uitkomsten zijn een goede grond voor selectie op basis van het eindexamencijfer (gewogen loting). Hierbij moet wel de kanttekening geplaatst worden dat de groep scholieren uit de VWO-stroming van 1982 en 1983 een andere groep is dan de scholieren van het huidige VWO (en het studiehuis in de Tweede Fase). Opmerkelijk is wel dat dat onderzoek van dezelfde auteur is als het onderzoek uit 1978 waarvan de uitkomst juist werd gebruikt als argument tegen directe toelating op basis van hoge eindexamencijfers. ${ }^{3}$

Een hoog eindexamengemiddelde heeft in het systeem van gewogen loting en directe toelating een positieve invloed op de inlootkans. Het eindexamengemiddelde wordt voor de helft bepaald door de resultaten op het schoolexamen en voor de andere helft door de score op het centrale eindexamen. Maar er zijn ook vakken waarvoor alleen een schoolexamen moet worden afgelegd. Het centrale eindexamen is op alle middelbare scholen in Nederland gelijk. Het schoolexamen kan echter verschillen. Deze verschillen zitten o.a. in het aantal herkansingsmogelijkheden per school, het schooljaar waarin bepaalde vakken afgesloten moeten zijn en de eisen die aan de leerlingen worden gesteld (het zogenaamde niveau van de toets).

De keuze voor een bepaalde middelbare school kan dus invloed hebben op de inlootkans voor de studie geneeskunde. Een bijzondere groep is het particuliere onderwijs. Deze scholen voorzien in speciale klasjes met als doel een gemiddeld eindexamencijfer boven de acht te halen en zo directe toegang tot de opleiding genees- kunde te krijgen. ${ }^{6}$ Cijfers van 1998 tot 2005 van de Algemene Onderwijsbond laten zien dat scholieren van twee particuliere instellingen op hun schoolonderzoeken gemiddeld respectievelijk 0.63 en 1 punt hoger scoren dan op het centrale eindexamen. ${ }^{7}$

Ook aan het loten kleven een aantal nadelen. Studenten kunnen maximaal drie maal meeloten. Inloten is daarnaast onafhankelijk van de voorkeur voor de faculteit waaraan men de opleiding wenst te volgen. Wanneer een student pas na twee of drie keer wordt ingeloot, ontstaan er verloren opleidingsjaren. Wanneer een student helemaal niet wordt ingeloot moet deze genoegen nemen met een opleiding van tweede keus, en inherent hieraan met een gewijzigd toekomstperspectief. Studenten kunnen zich niet gelijktijdig voor twee studies met een numerus fixus inschrijven. Dit kan ertoe leiden dat een student na uitloting ook niet bij zijn/haar opleiding van tweede keus terecht kan en moet uitwijken naar een opleiding van derde, vierde of zelfs van vijfde keuze.

\section{Decentrale selectie}

Sinds 2000 biedt de Wet Hoger Onderwijs en Wetenschappelijk Onderzoek de mogelijkheid om studenten voor opleidingen met een numerus fixus te selecteren. In het eerste jaar van invoering bij de Leidse en de Utrechtse faculteit was er direct tevredenheid. ${ }^{8}$ Zowel deelnemers als docenten uit Leiden en Utrecht waren enthousiast en de docenten ervaarden het als een uitdaging om met een zeer gemotiveerde groep studenten te mogen werken. Ten Cate en Hendrix geven wel aan dat motivatie lastig objectiveerbaar is. Ook wijzen zij erop dat voor een faculteit Geneeskunde niet het verleden van de kandidaat, maar juist diens toekomst relevant is, terwijl de politiek met decentrale selectie vooral het gedrag van de scholier wil beïn- 
vloeden. $\mathrm{Al}$ in 2002 stelde het KNMG Studentenplatform dat vanuit de studenten geredeneerd decentrale selectie vanuit de laatstgenoemde gedachte wenselijk is. ${ }^{9}$ Aankomende studenten kunnen door deze vorm van selectie meer invloed uitoefenen op toelating tot de studie van hun eigen keuze en ook scholieren met modale eindexamencijfers hebben zo een redelijke kans om in aanmerking te komen voor de studie geneeskunde. Maar de decentrale selectie in de toenmalige vorm had ook nadelen. Er waren logistieke problemen en niet alle faculteiten deden aan decentrale selectie. Bovendien waren de procedures per faculteit verschillend en niet altijd even inzichtelijk. Ook liet de informatievoorziening aan studenten te wensen over.

De commissie Sorgdrager (2003), die het experiment met decentrale selectie voor de regering evalueerde, was positief en wilde de decentrale selectie uitbreiden. ${ }^{10}$ Ook de door de faculteiten Geneeskunde zelf verrichte nadere evaluaties wezen erop dat selectie werkt. De decentraal geplaatste studenten van het ErasmusMC studeerden sneller, vielen drie maal minder uit en deden meer extracurriculaire activiteiten dan loters. ${ }^{11-12}$ Ook de studenten van de Universiteit van Amsterdam die na decentrale selectie toegelaten werden, waren significant meer gemotiveerd dan studenten die door middel van loting of directe toegang waren gestart; ook deden zij meer extracurriculaire activiteiten (vaak gezondheidszorg gerelateerd) tijdens de studie geneeskunde dan de andere studenten. ${ }^{13}$

In opdracht van de regering onderzocht de commissie 'Ruim baan voor talent' de mogelijkheden van selectie aan de poort voor diverse opleidingen. ${ }^{14-15} \mathrm{Zij}$ doet in haar eindrapport de aanbeveling dat opleidingen met een numerus fixus, in plaats van loting, selectie aan de poort zouden moeten kunnen toepassen. Ook het KNMG Studentenplatform is anno 2009 onder bepaalde voorwaarden voorstander van decentrale selectie maar dan wel naast een numerus fixus. Hierbij is het ontwikkelen van acht vergelijkbare decentrale selectieprocedures op alle faculteiten wenselijk.

Afschaffing van gewogen loting is vooralsnog niet aan de orde: eerst moet er meer onderzoek komen naar de verschillen in het toekomstig klinisch functioneren tussen de decentraal geselecteerde groep, de groep met een gemiddeld eindexamencijfer boven de acht en de groep met gewogen loting. Het gaat namelijk niet alleen om de kwaliteit van de student, maar ook om de arts van de toekomst. ${ }^{16}$

\section{Instroomregulatie}

De overheid probeert de instroom van studenten af te stemmen op de behoefte aan artsen in de toekomst. Hierbij doet zich het probleem voor dat het beleid van de overheid bij het reguleren van de instroom achterloopt op de ontwikkelingen in de praktijk. Dit verschijnsel wordt 'varkenscyclus' genoemd en is een bekend fenomeen bij de overheidsregulatie van medische opleiding in diverse Europese landen. ${ }^{17-18}$

Ook in Nederland doet dit verschijnsel zich voor. Zo was er in 2000 vanwege de krapte op de arbeidsmarkt sprake van de mogelijkheid de opleiding Geneeskunde te verkorten, zodat studenten sneller aan het werk konden. Het KNMG Studentenplatform was toen van mening dat er aan het inkorten van de basisopleiding te veel negatieve aspecten zaten, o.a. dat verkorting ten koste kan gaan van de kwaliteit. ${ }^{19} \mathrm{Er}$ kwam een andere oplossing; de instroom ging omhoog en meer studenten mochten starten met de opleiding Geneeskunde.

Op dit moment, ruim acht jaar later, is er geen sprake meer van krapte op de arbeidsmarkt. Het tegenovergestelde is het geval. Ter bevordering van de marktwerking heeft dit tussentijds echter niet geleid tot het naar het beneden bijstellen van de de 
instroom van studenten, met als eventueel gevolg een toename van werkloosheid onder (basis)artsen. In het rapport van het Capaciteitsorgaan uit 2008 is de ontwikkeling van de pool basisartsen in kaart gebracht. Afgelopen jaren (2000-2007) is die pool van basisartsen onder de 40 jaar gegroeid van 6.600 naar 7.300 en deze zal naar verwachting stijgen naar 10.600 in $2015 .{ }^{20}$ Hierbij is overigens ook de toegenomen instroom in de vervolgopleidingen meegeteld, maar verhoudingsgewijs loopt dit niet parallel, wat een enorme stijging van de basisartsen tot gevolg zal hebben.

Het verhogen van de numerus fixus heeft, naast de genoemde massaliteit in de collegebanken, ook andere nadelige gevolgen voor de toekomstige dokters. Door de grote instroom zullen er meer studenten afstuderen als basisarts. Zoals eerder genoemd is het gevolg hiervan dat er onvoldoende specialisatieplaatsen voor al deze basisartsen beschikbaar zullen zijn. ${ }^{21}$ De periode vanaf het afronden van de basisopleiding tot de start met de specialisatie zal langer worden doordat diplomadevaluatie ontstaat. Niet langer het artsdiploma is voldoende om in opleiding te komen. Door de grote concurrentie van basisartsen onderling zijn een promotie, werkervaring en netwerk belangrijke criteria voor instroom geworden. Het zal daardoor logischerwijs moeilijker worden om in opleiding te komen bij het specialisme van de eerste keuze.

In dit licht is het belangrijk dat er een schakeljaar komt. Het schakeljaar geeft de student in het laatste jaar van de basisopleiding de mogelijkheid kennis en ervaring op te doen en contacten te leggen in een specialisatie van voorkeur. De student kan zo wellicht eerder een opleidingsplek bemachtigen doordat men sneller zelfstandig werkt en verantwoordelijkheid heeft én meer praktische ervaring kan vergaren. ${ }^{22-23}$ Studenten moeten sneller dan nu hun basisen vervolgopleiding kunnen afronden. Het schakeljaar kan dit probleem alleen niet oplossen. Ook zou de instroom in de vervolgopleiding beter moeten aansluiten bij het aantal instromers in de basisopleiding.

\section{Uitkomsten studentenquêtes}

Jaarlijks voert het KNMG Studentenplatform een enquête uit onder al haar studentleden, inmiddels meer dan 10.000. Uit een in 2004 verricht onderzoek onder 1500 studentleden, met 428 respondenten (representatief verdeeld over alle faculteiten), blijkt dat er in de toekomst aanzienlijke bereidheid is tot deeltijdwerken onder zowel vrouwelijke als mannelijke studenten. Van de ondervraagde studenten wil 54\% de vervolgopleiding in deeltijd doen en na de vervolgopleiding wil $80 \%$ van de ondervraagde studenten in deeltijd werken. ${ }^{24} \mathrm{De}$ bereidheid tot deeltijdwerken zorgt enerzijds mogelijk voor een beperking van de werkloosheid onder basisartsen, maar anderzijds kunnen deze cijfers ook wijzen op een mogelijke vergroting van de behoefte aan medisch specialisten. Het is niet uitsluitend de werkloosheid die bij het ophogen van de numerus fixus op kosten van de maatschappij komt te staan. Geneeskunde is immers één van de duurste opleidingen; bij werkloosheid is de investering in de opleiding van deze werkloze zinloos geweest.

Daarnaast kan de grote instroom van studenten geneeskunde ook nadelige gevolgen op de kwaliteit van het onderwijs hebben. Uit de eerder genoemde enquête van het KNMG Studentenplatform bleek dat $61 \%$ van de studenten vindt dat de kwaliteit van onderwijs te lijden heeft onder het grote aantal studenten. Bijna de helft oordeelde dat er onvoldoende persoonlijk contact is tussen studenten en docenten tijdens de preklinische fase van de basisopleiding. Volgens 39\% is dit ook in de coschapfase het geval. ${ }^{25}$ Hoewel onafhankelijke visitaties van de Vereniging van Samenwerkende Nederlandse Universiteiten 
(VSNU) laten zien dat alle Nederlandse faculteiten (dus inclusief Groningen en Rotterdam met een relatief hogere instroom) een goede artsenopleiding realiseren, geeft dit geen inzicht in de mening van studenten. ${ }^{26}$ In de jaarlijkse Elsevier enquêtes worden studenten ondervraagd en zij blijken behoorlijk tevreden te zijn over de opleiding geneeskunde. ${ }^{27}$ Deze cijfers zijn echter gebaseerd op een steekproef onder een onbekend aantal studenten en hoogleraren. Ons onderzoek, waarin een ruime meerderheid van de studenten aangeeft dat de kwaliteit lijdt onder de grote aantallen medestudenten, mag niet onderbelicht blijven.

\section{Vooruitblik}

Dan rest nog de vraag wat de toekomst ons brengt. Op politiek niveau is er een voorkeur voor marktwerking in de zorg in het algemeen en voor concurrentie tussen basisartsen. De gevolgen van beslissingen over de hoogte van de instroom in de opleidingen Geneeskunde die vandaag worden genomen zijn pas over vijf jaar zichtbaar. Minister Klink van Volksgezondheid, Welzijn en Sport streeft naar een overschot aan artsen met als doelstelling een vraaggeoriënteerde zorg. ${ }^{28}$ Door het verhogen van de instroom of het afschaffen van instroombeperking kunnen veel studenten opgeleid worden tot basisarts, met als nadeel dat een groot aantal van deze studenten die op kosten van de maatschappij worden opgeleid, in de toekomst werkloos zal zijn als basisarts. ${ }^{29}$ Ook kan de kwaliteit van deze basisartsen minder zijn dan voorheen, daar de hoge instroom van studenten mogelijk de kwaliteit van het onderwijs negatief zal beïnvloeden.

De invoering van het bachelor/mastersysteem kan eveneens zorgen voor een verandering. In de toekomst zal de start van de opleiding Geneeskunde wellicht niet meer het enige selectiemoment zijn. ${ }^{30}$ Het is niet ondenkbaar dat er een tweede nieuw selectiemoment komt bij de instroom in de master. De vierjarige opleiding Selective Utrecht Medical Master (SUMMA), met een evenknie in Maastricht, leidt op dit moment al op tot basisarts en arts-onderzoeker. De selectieprocedure geschiedt via 'open' bachelors biomedische wetenschappen of verwante opleidingen. In het kader van deze ontwikkeling kan men zich de vraag stellen of de bacheloropleiding Geneeskunde in de toekomst nog wel automatisch toegang zal geven tot de masteropleiding Geneeskunde. Komt er in de toekomst wellicht een algemene medische master die door middel van selectie toegankelijk is vanuit verschillende bachelorprogramma's?

Maar om met het goede nieuws te eindigen: de laatste berichten van minister Klink en de Tweede Kamer zijn positief gestemd en in lijn met dit artikel. ${ }^{31}$ De opleiding Geneeskunde zou sneller moeten kunnen reageren op de vraag naar artsen (met een bepaald specialisme). Flexibiliteit van de opleiding moet een middel zijn om beter in te spelen op de krapte aan specialistisch opgeleid personeel. De Raad voor de Volksgezondheid zal de planning van de opleidingen Geneeskunde onderzoeken en advies uitbrengen, ook over de mogelijke relatie tussen dit tekort en het opdrijven van de salarissen voor specialisten. Klink is hoe dan ook tegen het afschaffen van de numerus fixus: de universiteiten kunnen een grotere toestroom van studenten niet aan, aldus de minister.

\section{Conclusie}

In dit artikel kwamen zowel het capaciteitsvraagstuk als de wijze van selectie aan de orde. De historie van de numerus fixus geeft zicht op de schijnbare tegenstelling tussen het belang van onderwijskwaliteit en de maatschappelijke behoefte aan artsen. Lang is men van overheidswege terughou- 
dend geweest met instroombeperking voor geneeskunde en daarna met selectie op basis van eindexamencijfers. Selectie anders dan op cijfers is iets van de laatste jaren. De evaluaties van de decentrale selectieprocedures zijn positief en deze wijze van selectie heeft inmiddels haar plaats veroverd naast loting en directe toegang. Wellicht is dat ook de beste manier om de nadelen (als uitloten en oneigenlijke keuzebeperking) van de drie instroommethoden op zich zoveel mogelijk teniet te doen.

Het overheidsbeleid waarin het aantal toegelaten studenten vastgesteld wordt, loopt echter vaak achter bij de ontwikkelingen op de arbeidsmarkt. Ter compensatie van dit probleem worden kunstgrepen voorgesteld als het inkorten van de opleiding en het (te laat) verhogen van de instroom. Van beide maatregelen wordt verondersteld dat ze een negatief effect hebben op de kwaliteit van de studie Geneeskunde. Het nalaten van een instroomcorrectie op het moment dat duidelijk was dat er te veel basisartsen uitstroomden zorgde voor verlenging van het totale medische opleidingstraject en werkloosheid onder (basis)artsen. In de toekomst zou dit kunnen leiden tot stuwmeren van basisartsen en/of stuwmeren van medische bachelors. Geconcludeerd kan worden dat de ontwikkelingen van de afgelopen jaren, zoals in dit artikel zijn weergegeven, een goed beeld schetsen van de onvolmaaktheden van het numerus fixussysteem bij geneeskunde. In de toekomst zal het systeem nog meer uitgedaagd worden.

\section{Literatuur}

1. Loghem JJ van. Numerus clausus en numerus fixus. Ned Tijdschr Geneeskd 1960;104:1001-2. [Numerus clausus and numerus fixus. Dutch Medical Journal 1960;104:1001-2].

2. Loghem JJ van. Numerus fixus. Ned Tijdschr Geneeskd 1948;92:1202. [Numerus fixus. Dutch Medical Jounal 1948;92:1202].

3. Cohen-Schotanus J. Loting en rendement - studieresultaten van Groninger medische studenten sinds de numerus fixus. Groningen: Bureau Onderwijsontwikkeling Geneeskunde, RUG; 1978. [Lottery and number of graduates - performance of Groningen medical students after the introducing of the numerus clausus. Office of Development in Medical Education, University of Groningen; 1978].

4. www.ib-groep.nl

5. Cohen-Schotanus J, Muijtjes AMM, Reinders JJ, Agsteribbe J, Rossum HJM van, Vleuten CPM van der. The predictive validity of grade point average scores in a partial lottery medical school admission system. Med Educ 2006;40:1012-1019.

6. Weenink D, Regt A de. Particulier onderwijs in Nederland: wie kiest ervoor en waarom? Mens \& Maatschappij 2003;78(2):100-118. [Private education in the Netherlands: who choose it and why? People and Society 2003;78(2):100-118].

7. Algemeen Dagblad 9 juni 2006: http://www.ad.nl/ utrecht/article394952.ece.

8. Cate ThJ ten \& Hendrix HL De eerste ervaringen met selectie voor de artsopleiding. Ned Tijdschr Geneeskunde 2001;145:1364-1368. [Initial experiences with medical school admission procedures. Dutch Medical Journal 2001;145:1364-1368].

9. Nieboer ThE. Lot in eigen hand. Med Contact 2002;57:1824-1826. [Don't leave it to chance. Medical Contact 2002;57:1824-1826].

10. Sorgdrager W et al. De juiste student op de juiste plaats. Eindrapportage van de Begeleidingscommissie Decentrale Toelating. Bijlage Kamerstukken II 2003/04, 29388, nr.3. [The right student in the right place. Final report of the Advisory Committee on Decentralised Admission. Appendix to Government documents II, 2003/04,29388, nr.3.].

11. Themmen APN, Splinter TAW \& Urlings-Strop L. Decentrale selectie in het ErasmusMC. Presentatie op LMSO-congres 2006, Leiden. [Decentralised admission procedure at Erasmus Medical Centre. Presentation at LMSO conference 2006, Leiden].

12. Urlings-Strop LC, Stijnen T, Themmen AP, Splinter TA. Selection of medical students: a controlled experiment. Med Educ 2009 Feb;43(2):175-183.

13. Hulsman RL, Ende JS van der, Oort FJ, Michels RP, Casteelen G, Griffioen FM. Effectiveness of selection in medical school admissions: evaluation of the outcomes among freshmen. Med Educ 2007;41:369-377.

14. Kamerstukken dossier 29 819. [Government documents file 29-819].

15. Wegen voor Talent: Eindrapport 2007. Den Haag: december 2007 p 19. http://www.minocw.nl/documenten/ocw_WVT.pdf. [Weighting for talent: Final report 2007. The Hague: december 2007, p. 19].

16. Dekker JA. Een review van decentrale selectie en numerus fixus bij geneeskunde. Tijdschrift voor Hoger Onderwijs 2008;26(4):206-215. [A review of decentralised admission and numerus clausus in medical education. Journal of Higher Education 2008;26(4):206-215]. 
17. Doan BD, Levy D, Pavot J. Demographic forecasts of medical workforce supply in France (20002050). What numerus clausus for what future? Cah Sociol Demogr Med 2004;44(1):101-148.

18. Kievits F, Adriaanse MT. Vlaamse numerus clausus. Ned Tijdschr Geneeskd 2004;148:1605. [Flemish numerus clausus. Dutch Medical Journal 2004; 148:1605].

19. Nijboer M. Studenten zien weinig in kortere basisopleiding. Med Contact 2000;55(2):60-61. [Students have little confidence in shortened undergraduate medical curriculum. Medical Contact 2000;55(2): 60-61].

20. Capaciteitsorgaan. Capaciteitsplan 2008; Utrecht. [Capacity body. Capacity Plan 2008; Utrecht].

21. Lambregts M. Dringen geblazen. Arts in spe 2007 (2):24-26. [Start jostling. Doctors of the Future 2007(2):24-26].

22. Jong GM de, Rijken JJ. Brug tussen student en praktijk: schakeljaar snel landelijk invoeren. Med Contact 2005;60(41):1643-1645. [A bridge between student and practice: quick national introduction of transitional year. Medical Contact 2005;60(41): 1643-45].

23. Oosterhout WPJ van, Morsink M. Wel een schakeljaar in de basisopleiding geneeskunde. Tijdschrift voor Medisch Onderwijs 2007;26(4):195-196. [A connecting year is useful in the medical curriculum. Dutch Journal of Medical Education 2007;26(4): 195-196].

24. Conemans EB, Valentijn MS, Tillaart SAHM van den, Groeneveld KM, Roza SJ. Populariteit van deeltijd. Ned Tijdschr Geneeskd Studenten-editie maart 2006;9(1) p.7-8. [A preference for parttime. Dutch Medical Journal, student-edition, March 2006;9(1)p.7-8].

25. Broertjes JC, Rijken JJ, Noordman IJ, Vries S de. Numerus fixus: grenzen aan de groei? 2004 (intern platformstuk, opvraagbaar bij het KNMG Studentenplatform). [Numerus fixus: limitations to growth? 2004; internal document, available from KNMG Student Plaform].
26. http://www.vsnu.nl/web/show

27. Elsevier THEMA. De beste universiteiten, 9 oktober 2008 p.62-64, www.elsevier.nl [The best universities, October 9, 2008].

28. Ministerie van Volksgezondheid, Welzijn en Sport. Reactie Ab Klink naar aanleiding van het rapport capaciteitsplan 2008; 28 april 2008. [Ministry of Health, Welfare and Sports. Reaction of Ab Klink tot the capacity plan report 2008; 28 April 2008].

29. Dellen E van. Stel studie geneeskunde niet open, voorkom werkloosheid. NRC Handelsblad 17 mei 2008. [Do not allow unlimited admission to medical school, prevent unemployment. NRC Handelsblad 17 May 2008].

30. Oosterhout R van, Rynja S. Aan de poort van de faculteit. Arts in spe 2007;(3):24-26. [At the faculty gate. Doctors of the Future 2007; (3)24-26].

31. www.zorgvisie.nl 5 februari 2009 Nico van Wijk.

De auteurs*:

Mw. mr. drs. J.A. Dekker is coassistent ErasmusMC Rotterdam.

Mw. M.M.C. Lambregts is coassistent Isala Klinieken Zwolle.

Mw. drs. M.W. Heeren is arts, afgestudeerd aan het UMC Radboud, werkzaam bij Eureko/Achmea.

Mw. J.I. Hanemaayer is coassistent UMC Utrecht.

*De auteurs zijn lid of lid geweest van het KNMG Studentenplatform en publiceren namens dit platform.

\section{Correspondentieadres:}

Mw. J.A. Dekker, Schapendreef 435, 3034 ZM Rotterdam; e-mail eerste auteur: Judith_Anna_Dekker@hotmail.com; e-mail correspondentieadres KNMG Studentenplatform: secretarisstudentenplatform@fed.knmg.nl

Belangenconflict: geen gemeld

Financiële ondersteuning: geen gemeld

\section{Summary}

Since the nineteen seventies admission to medical school has been restricted (numerus clausus). This article discusses the (political) developments relating to medical school admission including admission procedures and the number of students admitted. After extensive political debate three admission mechanisms were established in 2009: admission based on a grade point average of 8 or higher on the national school-leaving examination, a weighted lottery and decentralised selection, i.e. admission based on criteria set by individual medical schools. Each method has its limitations but combined they can compensate for each other's weaknesses. Current policies are aimed at creating a surplus of doctors to stimulate market driven health care. A drawback of this policy is loss of educational quality and unemployment among medical school graduates.

In summary, the numerus clausus is an imperfect system driven by conflicting interests. In view of current developments (Bachelor/Master degree system and free market policies) we conclude that the numerus clausus will be facing some challenges. (Dekker JA, Lambregts MMC, Heeren MW, Hanemaayer J, for the KNMG Student Platform. Changes in medical school admission procedures. Capacity and justification. Dutch Journal of Medical Education 2009;28(4):-159-166.) 